\title{
Produção E FORMAÇÃo AUdiovisual “FORA do EIXo" NO BRASIL: O CASO do INSTITUTO FEdERAL dE GoIÁs
}

\author{
Renato Prado
}

\begin{abstract}
RESUMo
A produção cinematográfica e audiovisual, a exemplo dos grandes grupos de média, esteve historicamente concentrada nas mãos de poucos agentes em relação ao todo populacional. Este tipo de concentração favorece discursos hegemônicos e representações alienadas de culturas que não produzem seu próprio conteúdo. As políticas públicas de descentralização da produção audiovisual brasileira no século XXI estão a desempenhar um papel importante e bem-sucedido de aumento da produção em regiões fora do eixo Rio-São Paulo, principal centro econômico e de produção dos média do Brasil. As instituições de formação audiovisual que estão "fora do eixo" devem estar atentas a esta organização, preparando os estudantes para os desafios técnicos, sociais e culturais da descentralização da produção e do discurso. O Instituto Federal de Goiás (IFG) oferece desde 2015 o Bacharelado em Cinema e Audiovisual em Goiás, uma pequena cidade da região centro-oeste do Brasil. O curso tem obtido resultados importantes advindos de sua proposta pedagógica ao mesmo tempo em que tenta se consolidar e estabelecer ações de cooperação com outras instituições fora dos principais centros de média de seu país e do mundo.
\end{abstract}

Produção audiovisual; políticas públicas; educação; contra-hegemonia; Instituto Federal de Goiás; Brasil

\section{"OFF-AXIS" AUdIOVISUAL PRODUCTION AND EDUCATION IN BRAZIL: THE CASE OF THE FEDERAL INSTITUTE OF GOIÁS}

\begin{abstract}
Cinema's and audiovisual's production, like the major groups of media, has been historically concentrated in the hands of a few agents if compared to the whole population. This kind of concentration favors hegemonic speeches and alienated representations of cultures that does not produce its own content. Brazilian's public politics for the decentralization of audiovisual's production on the $21^{\text {st }}$ century are playing an important and successful role on the growth of the production outside the axis of Rio-São Paulo, principal economic and media center Brazil. The audiovisual education institutions placed "outside de axis" must be attentive of this situation, preparing students for technical, social and cultural challenges of the decentralization of the production and the speeches. The Federal Institute of Goiás (IFG) offers since 2015 the bachelor's degree in Cinema an Audiovisual in Goiás, a small city of Brazilian's center-west. The course has had important results from its pedagogic proposal as it tries to consolidate as a new institution and stablish cooperation actions with other institutions outside the major centers of media productions in its country and worldwide.
\end{abstract}

KEYWORDS

Audiovisual production; public policy; education; counter-hegemony; Instituto Federal de Goiás; Brazil 


\section{INTRODUÇÃO}

A motivação para escrever este artigo partiu de um convite que recebi para falar em uma mesa de discussão sobre "Formação Audiovisual Fora do Eixo: desafios e aproximações", promovida pela Universidade Estadual de Goiás (UEG) durante sua Semana do Audiovisual. Fui convidado para representar o Instituto Federal de Goiás (IFG) na condição de coordenador do Bacharelado em Cinema e Audiovisual. Ambas instituições ofertam os dois únicos cursos de graduação em Cinema e Audiovisual no estado de Goiás.

No Brasil fala-se no Eixo Rio-São Paulo para designar uma região específica do país em que se concentram as principais emissoras de televisão, as produtoras de cinema, os grandes grupos dos média, o centro financeiro e, portanto, certa cultura dominante em âmbito nacional. As pessoas que conhecem pouco do Brasil, geralmente através de conteúdos audiovisuais, muito provavelmente conhecem algo produzido no ou pelo Eixo Rio-São Paulo. Em outras regiões brasileiras ele é conhecido (o que facilitará a escrita deste artigo) simplesmente como "eixo".

As cidades de São Paulo e Rio de Janeiro são as capitais homônimas de seus estados. O Brasil, no entanto, é um território com 26 estados e um Distrito Federal, onde está localizada a capital, Brasília. O domínio econômico e cultural do eixo pode ser averiguado em diversos setores sociais, mas este artigo se concentrará na produção dos média, mais especificamente em cinema e audiovisual.

Para entender com a devida proporção o fato de se situar "fora do eixo" no Brasil é preciso ter em mente as dimensões geográficas de tal implicação. Muitos estados brasileiros são equivalentes ou maiores do que nações europeias em termos territoriais, mas, em média, com menor densidade demográfica e menos recursos locais (o que pode ser resumido de maneira grosseira em menor infraestrutura). Para se ter uma noção, o estado do Rio de Janeiro é o quarto menor estado em extensão territorial (similar ao tamanho da Estônia), enquanto o estado de São Paulo (com tamanho similar ao Reino Unido) é o $16 .^{\circ}$ menor. Quando se imagina a diversidade cultural brasileira é possível, para os estudiosos da comunicação, imaginar como um processo centralizado de produção dos média pode desconsiderar incontáveis nuances de realidades locais.

Este artigo falará de maneira breve sobre políticas públicas de descentralização do audiovisual no Brasil e do caso do Instituto Federal de Goiás, que oferece desde 2014 uma formação audiovisual pioneira no país, não se furtando, durante o caminho, em estabelecer relações entre audiovisual e educação. O objetivo não é esmiuçar todas as políticas públicas de descentralização e nem representar todas as formações que são oferecidas fora do eixo, mas sim tratar a particularidade de um caso para evidenciar o potencial de diferentes formações, arranjos produtivos e olhares para o setor do cinema e audiovisual.

O artigo percorrerá as bases econômicas que favorecerem a descentralização audiovisual e as possibilidades geradas pelas novas e abundantes trocas que ocorrem via audiovisual. Ao diferenciar ensino audiovisual de educação para o audiovisual, espera-se deixar mais clara a importância da oferta diversificada de cursos que não só têm consciência de suas particularidades, mas que partem delas para discutir e pensar o mundo e suas próprias comunidades. 


\section{Políticas de descentralização da produção audiovisual no Brasil E EM Goiás}

O governo federal brasileiro implementou novas políticas no setor cultural na primeira década do século XXI, o que se tornou uma espécie de padrão a ser replicado por governos estaduais e municipais. É necessário dizer que as ações do governo foram direcionadas a diversas áreas culturais e artísticas do país, mas para os fins deste trabalho serão abordadas apenas as ações mais destacadas que concernem ao setor audiovisual. É possível, com certa tranquilidade, afirmar que as ações geridas pelo Ministério da Cultura (MINC) através da Secretaria do Audiovisual (SAv), com sede em Brasília, e da Agência Nacional do Cinema (ANCINE), com sede no Rio de Janeiro, são as principais responsáveis pelo atual cenário da produção audiovisual brasileira.

A criação do Fundo Setorial do Audiovisual (FSA), que começou a ser operado pela ANCINE em 2008, é um marco nas ações de produção audiovisual do país. Inicialmente com 90 milhões de reais, o fundo chegou a 2018 operando mais de 700 milhões de reais anuais em investimentos para o setor audiovisual. Apesar de não ser uma das primeiras ações implementadas, esta é particularmente importante para o contexto atual pelo volume de investimentos e pela aplicação do conceito de descentralização da produção audiovisual como parte da política pública de fomento pelo governo. A descentralização via FSA se dá através de uma cota de $30 \%$ de todos os recursos reservada, obrigatoriamente, às regiões Norte, Nordeste e Centro-Oeste (onde está localizado o estado de Goiás).

A Lei 12.485/2011 estabeleceu uma cota de conteúdo nacional nos canais da televisão paga, o que aumentou sobremaneira a demanda por novas produções. Em 2016 a ANCINE divulgou um relatório' com dados de que a inserção de conteúdo nacional foi acima das cotas, o que revela que a inserção via lei conseguiu construir uma audiência que espera mais conteúdo nacional.

É necessário destacar, especialmente para o contexto do IFG, a criação dos Núcleos de Produção Digital (NPD) pela SAv. Os núcleos, cuja missão é promover ações de formação, difusão e apoio à produção independente, são locais que contam com alguma estrutura tecnológica voltada para produção audiovisual. A ideia central dos NPD é estimular a descentralização da produção apoiando produtores independentes com empréstimo de equipamentos, formando trabalhadores para o audiovisual através de oficinas, minicursos e cursos regulares (normalmente gratuitos) e estimulando o público a conhecer filmes, que muitas vezes nem chegam às salas de cinema, através de pequenos projetos como cineclubes e exibições em praças públicas ou lugares incomuns.

O marco cinematográfico simbólico que precede a atividade cinematográfica desenvolvida pelo o estado de Goiás no século XXI foi a criação do Festival Internacional de Cinema e Vídeo Ambiental (FICA) em 1999 pelo governo do estado, com premiação considerável e, ainda hoje, relevância dentro de sua temática na América Latina. Outros festivais foram criados em Goiás, sobretudo em Goiânia, sua capital, a partir dos anos 2000, o que permitiu que houvesse uma espécie de circuito de exibição e de influência nos realizadores locais, uma vez que o cinema independente passou a se fazer mais presente e a parecer tangível.

\footnotetext{
' Retirado de http://agenciabrasil.ebc.com.br/geral/noticia/2017-08/ancine-tv-paga-superou-cota-de-exibicao-de-conteudo-nacional-em-2016
} 
A “Lei Goyazes" (Lei $\left.n^{\circ} 13.613 / 2000\right)$, regulamentada desde 2001, foi o primeiro mecanismo público do estado para o fomento de atividades artísticas do setor cultural, incluindo o setor audiovisual. Seguindo o modelo de renúncia fiscal para as empresas investidoras, a exemplo da "Lei Rouanet" em âmbito nacional, a "Lei Goyazes" passou a ser mais utilizada no final da década dos anos 2000, quando sofreu alteração para aumentar o percentual de renúncia fiscal em seus investimentos.

O Fundo de Arte e Cultura de Goiás lançou seu primeiro edital em 2013. Desde então esta é a principal ação de dinamização artística do estado, com um volume que chegou a 33 milhões de reais em 2017, dos quais o audiovisual possui verba destacada por ser uma atividade mais cara e que emprega artistas e técnicos de diferentes áreas. É importante dizer que, à exemplo do FSA, o fundo estadual também reserva uma cota destinada à descentralização, neste caso destinada às cidades do interior do estado.

A criação de festivais de cinema (sobretudo em Goiânia), os cursos regulares e de curta duração na área audiovisual, a lei da televisão paga, as novas janelas de exibição e as políticas de descentralização da produção audiovisual são os componentes que permitiram o cenário atual da produção desse setor no estado de Goiás, que pôde experimentar neste século uma constante programação cultural e o crescimento do número de produtoras e produções.

O estudo intitulado "Cinema e TV em Goiás: catálogo da produção em Goiás 2017"2, realizado pela GOFilmes (Associação das Produtoras de Cinema e TV de Goiás) e apoiado pelo governo de Goiás, contabilizou que haviam 57 projetos audiovisuais em execução no estado por 18 empresas produtoras, em diferentes estágios de produção, naquele ano. Destes, 28 eram de longa-metragem, 3 telefilmes e 26 séries televisivas.

É interessante destacar que para acessar os recursos de descentralização do FSA anteriormente mencionados são exigidas uma série de contrapartidas, dentre elas a experiência das empresas produtoras com um mínimo de dois anos de constituição e o registro na própria ANCINE. Diferentemente do FSA, o fomento estadual e municipal (no caso de Goiânia) não se restringe a produtoras e atividades com retorno financeiro, sendo possível o acesso mesmo através de pessoa física (não jurídica) e com prestação de contas, ainda que rígida, diferenciada. Dentro desta lógica, é possível dizer que o acesso ao FSA por produtoras goianas deve aumentar nos próximos anos, levando em consideração as novas empresas que têm se constituído e ainda operam em âmbito estadual, muitas das quais, formadas por pessoas oriundas dos cursos de Cinema e Audiovisual do estado.

Os Bacharelados em Cinema e Audiovisual (BACINE) do IFG e da UEG dispõem, portanto, de um mundo do trabalho que permite manter os estudantes motivados pela possibilidade de experimentarem o trabalho profissional durante sua formação. O curso da UEG se tornou um bacharelado em Cinema e Audiovisual em 2014, mas já existia desde a primeira década dos anos 2000 com o nome de Comunicação Social - Audiovisual. O curso do IFG começou em 2015 (em 2014 teve início o curso técnico integrado ao

${ }^{2} \mathrm{O}$ estudo foi publicado sem ISSN e está disponível em https://drive.google.com/file/d/1ER4RhzKOtGpoTzp3zWLeRSuq TRcxO2_l/view 
ensino médio em Produção de Áudio e Vídeo, que será explicado mais adiante). O setor audiovisual do estado de Goiás, antes disso, só havia tido os agora extintos cursos de Rádio e Televisão e um curso tecnológico em Fotografia e Imagem, ofertado desde 2004, todos concentrados em Goiânia.

O BACINE do IFG conta, desde sua gênese, com um Núcleo de Produção Digital da SAv. O Núcleo de Produção de Digital de Goiás (NPD Goiás) tem sede no IFG Campus Cidade de Goiás e é coordenado pelo corpo docente específico da área. Em 2017 o IFG sediou um seminário que reuniu 16 NPD do país, o Centro Técnico do Audiovisual (CTAv), alguns institutos federais de outros estados que têm projetos audiovisuais - formais ou no âmbito da extensão - e outros convidados para troca de experiência, como representantes da zona de Cataguases (interior de Minas Gerais) e do Instituto Querô (da cidade de Santos). Discutiu-se o modelo de gestão dos NPD e as potencialidades das redes de núcleos e de institutos federais para ações de descentralização da produção audiovisual. Existe, portanto, uma disposição em se consolidar uma rede de formação audiovisual a partir dos agentes fora do eixo.

O IFG em parceria com o NPD Goiás já produziu um longa-metragem e mais de 50 curtas-metragens desde 2015. O NPD Goiás é o principal local de estágio audiovisual na região da cidade de Goiás e alicerce dos projetos de extensão que variam entre exibição, cinema e educação, cinema expandido, crítica e produção audiovisual. Os resultados do IFG seriam, provavelmente, bem aquém do que se tem hoje não fosse o apoio desta política pública, a exemplo do que acontece na cidade de Barra do Garças (próxima à cidade de Goiás, mas no estado vizinho, Mato Grosso), onde existe o NPD Araguaia em parceria com a Universidade Federal de Mato Grosso (UFMT), no Distrito Federal com o NPD Recanto das Emas, ligado ao Instituto Federal de Brasília e do que tende a acontecer no Instituto Federal de Mato Grosso do Sul (IFMS), na cidade de Campo Grande, com a instalação de mais um NPD. Goiás, Mato Grosso, Mato Grosso do Sul e Distrito Federal são as unidades federativas que integram a região Centro-Oeste do Brasil.

O desenrolar desses cenários evidencia que, em paralelo às ações de descentralização da produção, é necessário que exista, de maneira proporcional, a oferta formativa de profissionais. Durante as discussões levantadas na mesa redonda que motivou este artigo falou-se muito sobre as diferenças de se formar "fora-do-eixo" e o que isso poderia representar. Os recursos materiais não são os mesmos, obviamente, sem grandes estúdios e com menor presença de artistas renomados para alimentar um Star System³. Questões sobre os tipos de conteúdos também surgiram, não com a intenção de condicionar ou forçar os/as realizadores/as locais a um estilo ou restrição de temas, mas é fato que é preciso considerar com outros olhos o lugar de fala, de onde partem as produções e com quem se tenta estabelecer uma comunicação a partir das produções locais.

O que se coloca, em síntese, é a necessidade de produzir audiovisual não só por motivos econômicos, mas pela necessidade de pensar, valorizar e fortalecer as

\footnotetext{
3 Explicado em vários livros sobre história do cinema, o Star System foi o nome dado à estratégia de marketing adotada pelos estúdios de Hollywood a partir da década de 1920, quando começaram a investir na personalidade de atores e atrizes para que estes promovessem os filmes de maneira mais eficiente.
} 
especificidades de diferentes culturas a fim de vermos - e sermos vistos - através de histórias com mais produtores do que algumas dúzias de grandes empresas. Como expresso no desejo do diretor de cinema alemão Wim Wenders (2010, pp. 400-401):

\begin{abstract}
gostaria que os políticos, na Europa, na Ásia ou na América do Sul, entendessem quanto nossas culturas no futuro irão depender desse sentido de lugar e de vê-lo refletido nas nossas próprias histórias, contadas dentro de nossas fronteiras, em nossa própria linguagem. Só os nossos próprios sons e nossas próprias imagens podem manter vivas nossas identidades e o sentido de lugar e de pertencimento. Espero, portanto, que os governantes apoiem os cineastas locais, sua cultura de cinema local. Os documentários. Apoiem tudo o que é pequeno. O que é grande só quer ser ainda maior à custa do pequeno.
\end{abstract}

\title{
Audiovisual, ENSINO E EDUCAÇÃo
}

Quando, em alguma parte, setores populares da população começam a descobrir formas novas de luta e resistência, elas redescobrem também veIhas e novas formas de "atualizar" o seu saber, de torná-lo orgânico. (...) Eu não tenho dúvidas em afirmar que é entre as formas novas de participação popular, nas brechas da luta política, que, hoje em dia, surgem as experiências mais inovadoras da educação no Brasil. (Brandão, 2013, p. 112)

É cada vez mais necessária uma educação que considere as especificidades da linguagem audiovisual à medida que avançamos nessa sociedade dominada por ecrãs. Uma espécie de letramento para lidar com suas rotinas de maneira mais consciente, mesmo diante das mais variadas emoções que experimentamos em frente às telas. Nas palavras de Thompson (2009, p. 46) "não devemos perder de vista o fato de que, num mundo cada vez mais bombardeado por produtos das indústrias da mídia, uma nova e maior arena foi criada para o processo de autoformação".

Colocar-se na posição de ensinar o audiovisual básico não chega a ser um absurdo. Se há escolas fundamentais e cursos superiores dedicados a linguagens escritas, sonoras e visuais, estas ferramentas básicas da comunicação humana, é preciso também haver as escolas dedicadas ao audiovisual. Nosso escopo aqui, no entanto, se limitará à educação profissional e superior e ao papel que as instituições podem desempenhar para a construção de um cenário audiovisual mais diversificado.

É difícil imaginar que o papel das escolas de audiovisual se sustentará por muito tempo com maior ênfase no treinamento técnico - ainda que os estudantes adentrem os cursos ávidos por isto. Produzir audiovisual hoje não requer várias habilidades que eram essenciais há 30 anos, como era o caso do uso do fotômetro para se filmar em película. Vale lembrar que até o início deste século a maior parte do cinema presente nas salas de cinema comerciais era filmado em película. A película é um suporte fotossensível que 
não permite a visualização imediata de seu resultado final, de modo que os fotógrafos encarregados tinham obrigatoriamente que prever o resultado da exposição fotográfica em suas mentes, para isso o fotômetro era seu maior aliado.

É claro que há muitas habilidades, técnicas e monitoramentos digitais a se aprender, ainda que o setor industrial pareça se esforçar para automatizar o máximo possível. Essas informações, no entanto, não são segredo. As fontes de informação técnicas, ao contrário, abundam e estão disponíveis em diversas línguas através de conteúdos gratuitos online ou em livros de relativamente fácil acesso. Muitas pessoas podem comprar uma câmera e aprender técnicas pelo YouTube em pouco tempo. O mesmo acontece às demais áreas técnicas da cadeia audiovisual.

A situação que tento apresentar não é a de extinção de professores ou instituições de educação formal. Mesmo tecnicamente falando, um curso bem organizado e com docentes experientes pode poupar muito tempo de autodidatismo e experimentações ao iniciante. A hipótese que vislumbro é de que as facilidades técnicas - é mais difícil comprar o equipamento do que aprender a manuseá-lo - deixarão mais espaço para conversar sobre o trabalho em todos os seus outros aspectos psicológicos, estéticos e sociais.

Há pouco tempo ministrei um curso rápido, na própria cidade de Goiás, de como editar vídeos em celulares utilizando softwares gratuitos. Havia alunos do $5 .^{\circ}$ ano da educação fundamental ao $2 .^{\circ}$ ano do ensino médio, acompanhados de seus professores. Os alunos eram de diversas escolas da cidade, dos distritos rurais e de cidades vizinhas. Durante o curso, feito em um molde de "passo a passo", os monitores - adolescentes do curso Técnico Integrado em Produção do Áudio e Vídeo do IFG - praticamente só intervieram para "salvar" professores que ficaram perdidos. Quando terminava de explicar um passo, a maioria das perguntas dos estudantes era sobre as possibilidades que aquele passo abria ou sobre passos avançados que queriam adiantar. Ao final muitos vieram conversar comigo sobre vários outros softwares que eles já usavam e que facilitavam suas vidas. Os softwares eram realmente melhores, mas eram pagos e eu não podia usá-los no curso. Eles tampouco pagaram pelos aplicativos. Apesar de admirar, em alguns casos, a habilidade de hackear os aplicativos - e a vida -, eu não podia incentivar a prática. Foi bom momento para se falar sobre ética.

A contribuição maior de um curso robusto seria, portanto, a introdução de estudantes às rotinas do trabalho profissional. O mínimo esperado de um profissional é um bom nível de compreensão da linguagem, de parâmetros estéticos, de capacidade de realização e de compromisso ético para executar os trabalhos dentro dos padrões esperados pela sociedade - e até mesmo para transgredi-los de maneira consciente quando necessário.

Em um ambiente menos profissionalizado, mais autodidata, é comum que padrões éticos sejam quebrados, como o uso indevido de imagens de terceiros e violação de direitos autorais, sobretudo por novatos ávidos a adentrarem o mercado e se fazerem notar a qualquer custo. Quando o uso das habilidades audiovisuais deixa de ser amador, o nível de exigência e de responsabilidade pela produção e reprodução de imagens e sons cresce substancialmente. A experiência que permite a compreensão dos 
parâmetros específicos que norteiam a profissão é normalmente aprendida no contato com profissionais consolidados do mercado ou no ambiente formal de estudos, sem desconsiderar obviamente as interações sociais quotidianas.

Aqui é interessante que diferenciemos o ensino de audiovisual e a educação para o audiovisual. O primeiro seria o treinamento para um conjunto de técnicas que se utilizam dos recursos audiovisuais sem problematizá-los. A maior parte dos cursos livres online de hoje em dia faz isso. A segunda, em contrapartida, é aquela que abarca as questões de sensibilidade e empatia para com a expressão audiovisual do outro: quem fala, de onde fala, as escolhas estéticas, éticas, simbólicas e de significação que sustentam o discurso.

A questão colocada por Medeiros (2016, p. 192) é muito pertinente: “mas, (...) para que o filme deixe de ser apropriado como mera associação de imagens e possibilite a imanência não seria necessário pensar na construção de uma educação para a sensibilidade do olhar?". A educação para o audiovisual é uma ação de fomento à pluralidade cultural.

Os meios de difusão audiovisual de massa, até o princípio do século XXI, eram quase inacessíveis àqueles que desejavam ser emissores de conteúdo. Poucos eram os agentes que se encarregavam de representar o grande espectro de diversidade cultural no mundo e de escolher o que seria produzido. As plataformas de difusão hoje permitem uma interação audiovisual tão impressionante quanto impensável há 20 anos.

É sabido que a identificação é um fator chave da produção audiovisual tradicional e que os grandes agentes de produção usam isto para atingir determinado público-alvo de suas produções. O cineasta e escritor brasileiro Fernando Coni Campos (2003, p. 29) foi taxativo: "não existe boa história, em cinema, se não houver identificação entre o que acontece na tela e o espectador; sem que o espectador se sinta não um passivo olhador de coisas, mas que, também ele, se projete".

É possível verificar o potencial do público infantojuvenil, normalmente com mais tempo para se dedicar à fruição audiovisual, desde os anos de 1980. Na década de 2010, segundo relatórios da $\mathrm{ANCINE}^{4}$, pelo menos sete das 10 maiores bilheterias de cada ano no Brasil foram nesse segmento. É nítido, por exemplo, como "Os vingadores" (The avengers, Joss Whedon, 2012) é recheado de humor juvenil mesmo em situações em que os heróis estão lidando com uma provável catástrofe mundial. No filme The avengers: Ultron's age [Os vingadores: a era de Ultron] (Joss Whedon, 2015), durante uma missão, o Capitão América chama a atenção do Homem de Ferro para que ele use um linguajar mais adequado após ele ter dito um palavrão, e o que se segue é que a equipe começa a fazer uma espécie de bullying com o Capitão durante a missão, em meio a explosões e lutas.

No Brasil, a produção audiovisual do eixo, com maior domínio das telenovelas, mas também verificável no cinema, sempre foi responsável por abarcar diversas particularidades, com o destaque auditivo para os sotaques, das mais variadas regiões do país.

${ }^{4}$ A ANCINE publica diversos relatórios e análises de impacto das políticas públicas no mercado audiovisual brasileiro, disponíveis em https://www.ancine.gov.br/ 
É possível dizer que a produção do eixo está para o Brasil como a produção dos Estados Unidas da América (EUA) está para o mundo. Para os nativos das regiões representadas pelo discurso hegemónico (no Brasil ou no mundo) é demasiadamente difícil se identificar com uma representação caricata e superficial de sua própria cultura.

Episódios de representação alienada não faltam. Os filmes históricos produzidos pelos EUA são no idioma inglês, mesmo que se esforcem para reconstituir toda a atmosfera de Atenas e Tróia, ou do império romano, ou dos vikings.

A evolução e a diversificação do discurso hegemónico também não são novidades. Os principais produtores de comunicação sempre precisaram encontrar um equilíbrio entre os seus anseios e os desejos da audiência, que garante o financiamento de novas produções. As novas dinâmicas de produção e distribuição, no entanto, têm permitido que grandes players do cenário estadunidense invistam em produções descentralizadas, pelo menos em relação ao próprio Estados Unidos, a fim de promover narrativas menos autocentradas na cultura americana, caso de alguns originais da Netflix, como as séries La casa de papel e, a brasileira, $3 \%$.

O exemplo da Netflix não é em si uma situação redentora em relação às produções dos grandes meios e a produção contra-hegemónica. O estilo de distribuição e consumo que consagrou a Netflix, e que já começa a ganhar concorrentes de peso, é que pode promover profundas mudanças nas possibilidades de produção audiovisual na medida em que aumenta a chance de produtos audiovisuais, dentre eles os de produção independente, serem assistidos, difundidos, comentados, enfim, conhecidos.

A educação para o audiovisual pode desempenhar o papel de preparar os novos profissionais, que serão também os realizadores das próximas décadas, para a produção e a fruição cultural descentralizada, contra-hegemónica, em que as sociedades possam se representar e dialogar com outras a partir de suas falas, sem a interferência de grandes mediadores, fazendo com que o audiovisual seja para a sociedade, cada vez mais, como o cinema almejado por Wenders (2010, p. 400): “o cinema tem, portanto, uma enorme tarefa. O cinema local. O cinema regional. O cinema nacional. O cinema 'específico'. Só esse tipo de cinema comunica de verdade. Ensina a ter respeito pelo outro, pelo desconhecido, pelo diferente".

\section{A PROPOSTA DE FORMAÇÃo AUdIOVISUAL DO IFG}

A lei de criação dos Institutos Federais é de 2008. Os então Centros Federais de Educação Tecnológicas (CEFET), passaram a se chamar Institutos Federais (com algumas exceções). A partir de então a principal oferta da rede - hoje com mais de 600 campi - são os cursos técnicos integrados de nível médio ${ }^{5}$ e os cursos superiores, ainda que exista oferta de cursos de formação inicial e continuada (FIC), subsequentes e pós-graduações. O estado de Goiás possui o Instituto Federal de Goiás (IFG), com 14 campi, e o Instituto Federal Goiano (IFGoiano), com 12 campi.

\footnotetext{
${ }^{5}$ Equivalente ao ensino secundário em Portugal.
} 
O IFG oferece formação audiovisual regular em apenas um de seus campi, o Campus Cidade de Goiás - o menor deles, por sinal. Antiga capital do estado, a cidade de Goiás é um município com pouco mais de 22.000 habitantes $^{6}$, segundo o último Censo do Instituto Brasileiro de Geografia e Estatística (IBGE), cujo um terço da população habita áreas rurais e distritos afastados em um raio de até $50 \mathrm{~km}$ por vias rodoviárias. A cidade está a $136 \mathrm{~km}$ da capital, Goiânia, que tem 1,4 milhão de habitantes7 ${ }^{7}$ O campus oferece também outros três cursos técnicos integrados de nível médio em Edificações, Agroecologia e Artesanato, além da Licenciatura ${ }^{8}$ em Artes Visuais.

A formação audiovisual oferecida pelo IFG é constituída pelo curso Técnico Integrado ao Ensino Médio em Produção de Áudio e Vídeo, com duração de três anos, e pelo Bacharelado em Cinema e Audiovisual, com duração de quatro anos. Trata-se de uma oferta verticalizada de sete anos de educação formal, a exemplo do que acontece em vários institutos pelo Brasil, mas em áreas diferentes. É necessário dizer que esta foi a primeira formação nestes moldes, dentro da área de audiovisual, a ser ofertada no Brasil. A tendência é que o Instituto Federal de Brasília (IFB) ofereça em breve uma formação similar, mas com a Licenciatura em Cinema e Audiovisual como opção de curso superior. Somos, atualmente, dez professores da área audiovisual que se dividem entre as demandas dos dois cursos.

Oferecer uma formação robusta em um local considerado pequeno com um mercado audiovisual local quase que inteiramente amador, desprovido de produtoras, de produção publicitária, de produção jornalística, com apenas algumas produções culturais sazonais é o primeiro grande desafio de se estar fora do eixo. No caso do IFG, o curso está no interior do interior - o curso da UEG é ofertado em Goiânia. O cenário de trabalho, em princípio, com poucas oportunidades para os estudantes, demanda muito mais de uma política estudantil que os auxilie na permanência e êxito, o que ainda não tem acontecido a contento.

O aumento do investimento na proposta educacional dos institutos federais é um anseio da rede de institutos espalhados pelo Brasil. O orçamento do IFG é mais de cinco vezes menor que a Universidade Federal de Goiás (UFG) - para demonstrar como parâmetro uma instituição pública do mesmo estado. Os estudantes de nível superior não dispõem de uma política que facilite a alimentação, como acontece nos cursos integrais de nível médio em que os estudantes podem almoçar nos refeitórios de maneira gratuita ou recebem um auxílio financeiro nos campi que não dispõem de refeitório. Além de aumentar o investimento (algo que os grandes grupos de educação privada e os que são a favor de privatizações em todos os setores se esforçam para impedir), ações de cooperação estrutural entre as instituições de ensino superior públicas de todos os âmbitos poderiam ser bem mais úteis à sociedade do que se comportarem como concorrentes, por vezes redundando na oferta de cursos e de ampliações prediais.

\footnotetext{
${ }^{6}$ Retirado de https://www.ibge.gov.br/cidades-e-estados/go/goias.html?

7 Retirado de https://www.ibge.gov.br/cidades-e-estados/go/goiania.html?

${ }^{8}$ Licenciaturas no Brasil são cursos com ênfase na formação de professores.
} 
A conjuntura socioeconômica da região, no entanto, não pegou a instituição de surpresa. O próprio estudo que precedeu a abertura em 2014 do curso técnico e em 2015 do bacharelado já apontava para os fatores mencionados. O fato, por si só, da cidade de Goiás sediar o Festival Internacional de Cinema e Vídeo Ambiental (FICA) - o maior festival de cinema do estado - não era suficiente para embasar a oferta do curso que depende de uma infraestrutura considerada de alto custo.

As desvantagens, no entanto, até certo ponto, são características que também podem ser aproveitadas pelo projeto educacional. A cidade pequena permite o custo de vida mais baixo, menos tempo gasto com deslocamentos de toda ordem, maior contato com os colegas, mais tempo para a própria vida - de onde surgem as criações.

As produções são realizadas dentro de uma lógica diferenciada. Apesar da estrutura industrial hiper-hierarquizada dos mercados audiovisuais tradicionais serem abordadas em sala de aula, os ambientes práticos têm sempre uma escala menor do que são as produções do eixo. O espírito de produção "guerrilheiro" está sempre presente e dificilmente um membro da equipe desempenha apenas uma função.

É óbvio que esta situação não agrada a todos. Há docentes e discentes que sofrem com a monotonia, com a falta de uma oferta de programação cinematográfica diversificada em salas de cinema e com os atritos com o quinhão mais conservador da cidade - que tem certo apreço por colégios militares. Há quem peça transferência e até exoneração.

O cenário é bucólico, aos pés da Serra Dourada, num município reconhecido pela Unesco como Patrimônio da Humanidade, mas não chega a ser romântico. As dificuldades são reais e, por vezes, duras. As conquistas, as produções acabadas e a inserção dos estudantes no mundo do trabalho são gratificantes. Eles, felizmente, já têm chegado aos últimos períodos do bacharelado cheios de agendas profissionais para cumprir.

A formação verticalizada é um aspecto importante que poderemos analisar com maior precisão em alguns anos. O bacharelado tem, neste momento, cerca de sete alunos oriundos do ensino médio integrado em Produção de Áudio e Vídeo que poderão se formar aos 21, 22 anos tendo experimentado os sete anos do percurso formativo da instituição.

Estudantes das regiões Norte e Nordeste têm escolhido o IFG para se formar em audiovisual. A presença culturalmente diversificada enriquece a experiência do curso e torna evidente que existem pessoas optando pela formação diferente da tradicional.

A comunidade audiovisual do IFG em 2018 foi de cerca 150 pessoas entre estudantes e professores. O BACINE formou sua primeira turma em dezembro de 2018 . $\mathrm{O}$ curso está estruturado em ciclos de realização documental, ficcional e animação/experimental. Esta dinâmica de funcionamento tem garantido a produção de pelo menos oito curtas-metragens por ano. O NPD Goiás apoia as produções do IFG e da comunidade da região. Muitos filmes de alunos e professores têm recebido prêmios e menções honrosas em festivais cinematográficos brasileiros. O caso de maior destaque internacional foi o filme Terra e luz (2017), escrito e dirigido pelo professor do IFG Renné França, com equipe formada por professores e alunos e um orçamento de menos de 7.000 reais $(2.000 €)$ que ganhou prêmios em mostras temáticas no Brasil, México e França, 
assinou contrato de distribuição com a O2 Filmes, empresa sediada no eixo, e agora está disponível em plataformas on-demand.

É óbvio que o cinema abordado no IFG não ignora a história estadunidense e nem grandes autores de outros continentes. A ideia não é incentivar uma produção autocentrada, ensimesmada, que imponha um regionalismo forçado. O que acreditamos fazer a diferença é, em meios aos exemplos mundiais de cinema, às vezes intangíveis em orçamento, discutir também os cinema regionais, com narrativas diversificadas, com meios de produções menores, que permitem uma educação mais próxima das metodologias desenvolvidas por Paulo Freire (2001), usando o quotidiano dos estudantes para construir pensamentos livres, ou seja, considerando sua própria experiência de vida como ponto de partida para pensar o mundo.

Precisamos do mundo para melhorarmos nossa comunidade, mas não podemos deixar de sermos contagiados por ela, e se, como acredita Maffesoli (2000, p. 27), "o ideal comunitário de bairro ou aldeia, age mais por contaminação do imaginário coletivo do que por persuasão de uma razão social", a presença audiovisual há de ser uma dimensão importante do fortalecimento das culturas regionais.

A formação oferecida pelo IFG está voltada para o profissional que tem consciência do discurso hegemônico e a perspectiva real de trabalhar com cinema e audiovisual a partir da região Centro-Oeste ou sua região de origem. A mudança para o eixo não é algo rechaçado, desestimulado ou mesmo criticado no âmbito do curso. A questão perpassa muito mais pela intenção de se construir um ambiente profissional em que uma mudança, caso ocorra, seja por interesses particulares e não por falta de opções ou perspectivas de trabalho em sua região de origem.

A literatura mostra que é possível falar em globalização cultural, pelo menos para quem tem possibilidade de adquirir bens culturais (Morin, 2010, p. 37). A relevância, o alcance e o poder de influência da produção audiovisual de pequenos agentes não pode ser subestimada em nenhuma de suas possibilidades. As instituições de formação são um braço importante não só da profissionalização técnica, que é essencial para a descentralização da produção audiovisual, mas também de estímulo ao discurso não-alienado, que se representa, entende suas origens e se comunica com outras culturas de maneira consciente. Em um cenário assim, a troca de hábitos culturais acontece mais pela admiração e respeito ao outro do que por um volume imenso de vinculações massificantes dos centros que dominam a produção de conteúdo e, portanto, as narrativas da história.

Imaginar a escala de troca de informações por vias audiovisuais que ocorrem neste momento no mundo pode ser algo estimulante ou desesperador, a depender do ponto de vista. O conceito de cultura-mundo desenvolvido por Lipovetsky e Serroy (2010) vem à mente, mais especificamente a necessidade de civilização da cultura-mundo. $O$ interessante é que os autores falam em civilização e não em domesticação, como o que é colocado por algumas correntes educacionais mais conservadoras. Os autores atribuem aos artistas uma grande parcela de responsabilidade na civilização da cultura-mundo, situando a arte como um pilar da sociedade que, ao promover a experiência sensível, serviria para reduzir a desorientação dos indivíduos e promover seu desenvolvimento 
interno, sua autoestima e sua capacidade autónoma. É certo que as escolas que preparam os artistas devem também ter isso em mente.

\section{CONSIDERAÇÕES FINAIS}

A descentralização da produção audiovisual e a gradual facilitação da circulação destes conteúdos abrem perspectivas culturais importantes em âmbito mundial. É óbvio que toda mudança em grande escala pode ser uma fenda para optimismos e pessimismos, mas acima disto, o que se pode dizer é que experimentaremos cada vez mais a pulverização dos emissores que podem ser vistos em plataformas de reprodução massiva.

O fluxo audiovisual proporcionado pela internet não se restringe à produção dos grandes meios e nem à produção profissional no que tange a seus parâmetros éticos e de direitos. O que chamo de "Audiovisual Selvagem", ou seja, feito por não profissionais, sem os compromissos das rotinas próprias da profissão, já circulam com grandes audiências e com interesses diversos em que pessoas se aglutinam em incontáveis nichos em maior ou menor escala.

A educação para o audiovisual é uma forma de se organizar de maneira consciente em relação à produção hegemônica e às trocas culturais, de maneira a pensar e participar dos diálogos étnico-culturais do mundo ao invés de agirmos como meros consumidores de conteúdo ou, por outro lado, alimentadores de plataformas online, cujos editores são algoritmos, que usam os conteúdos para vender anúncios. A escola ou universidade que forma artistas e comunicadores forma também pessoas que dialogarão em grande escala e atuarão na civilização da cultura-mundo.

Formar-se "fora do eixo" é, e precisa ser desde seu planejamento, uma experiência diferenciada da tradicional. Por mais que o indivíduo tenha a base para buscar as maneiras de estar nos grandes centros de produção, se for de sua vontade, a mera emulação do que acontece nos grandes centros de produção é algo não só falso, mas que ignora muitas possibilidades de criação que tendem a enriquecer a cultura mundial. Formar-se de maneira diversa deve constar nos objetivos dos itinerários formativos propostos pelas instituições de educação.

Os atuais números e as perspectivas econômicas mostram que é possível ser produtor audiovisual nas regiões Centro-Oeste, Norte e Nordeste do Brasil. A vivência em regiões diferentes implica em profissionais com repertórios culturais diversos. Esses realizadores, os "fora do eixo", serão parte importante do audiovisual brasileiro dos próximos anos, desobrigando o "eixo" de ter que representar outras regiões e culturas do Brasil de forma caricata, pouco conhecedora das artes de viver reais que são ali cultivadas. Em termos de oportunidade, a situação explorada neste artigo não se difere muito do que é encontrado nos chamados países de "terceiro mundo" que têm populações conectadas à internet. $\mathrm{O}$ mundo está prestes a conhecer representações culturais genuínas, diferentes dos aspectos culturais "tipo exportação", indo para além dos estereótipos sociais. A atuação do Instituto Federal de Goiás visa essa formação diversificada, contra-hegemônica e tende, num futuro próximo, a construir pontes que facilitem o fluxo de conteúdos audiovisuais entre América latina e África lusófona. 


\section{REFERÊNCIAS}

ANCINE - Observatório Brasileiro do Cinema e Audiovisual. Retirado de https://oca.ancine.gov.br/

Brandão, C. R. (2013). O que é educação. São Paulo: Editora Brasiliense.

Campos, F. C. (2003). Cinema: sonho e lucidez. Rio de Janeiro: Azougue.

Cinema e TV em Goiás. Catálogo da produção audiovisual em Goiás 2017. Brasil: Governo de Goiás. Retirado de https://drive.google.com/file/d/1ER4RhzKOtGpoTzp3zWLeRSuqTRcxo2_I/view

Freire, P. (2001). Conscientização: teoria e prática da libertação: uma introdução ao pensamento de Paulo Freire. São Paulo: Centauro.

Lei $n^{\circ} 13.613 / 2000$, de 16 de maio, República Federativa do Brasil.

Lei $n^{\circ} 12.485 / 2011$, de 12 de setembro, República Federativa do Brasil.

Lipovetsky, G. \& Serroy, J. (2010). A cultura-mundo. Resposta a uma sociedade desorientada. Lisboa: Edições 70.

Lisboa, V. (2017, 10 de agosto). Ancine: TV paga superou cota de exibição de conteúdo nacional em 2016. Agência Brasil. Retirado de http://agenciabrasil.ebc.com.br/geral/noticia/2017-08/ ancine-tv-paga-superou-cota-de-exibicao-de-conteudo-nacional-em-2016

Maffesoli, M. (2000). O tempo das tribos: o declínio do individualismo nas sociedades de massa. Rio de Janeiro: Forense Universitária.

Medeiros, S. A. L. de (2016). Imagens educativas no cinema. Curitiba: Appris.

Morin, E. (2010). O mundo que eu vi e vivi. In G. Axt \& F. L. Schüler (Eds.), Fronteiras do pensamento (pp. 2543). Rio de Janeiro: Civilização Brasileira.

Thompson, J. B. (2009). A mídia e a modernidade: uma teoria social da mídia. Petrópolis: Editora Vozes.

Wenders, W. (2010). Cinema além-fronteiras. In G. Axt \& F. L. Schüler (Eds.), Fronteiras do pensamento (pp. 389-404). Rio de Janeiro: Civilização Brasileira.

Whedon, J. [Realizador] (2015). The avengers: age of Ultron. [Filme]. Marvel Studios.

\section{NotA BIOGRÁFICA}

Renato Prado é Professor do Instituto Federal de Goiás. Fotógrafo e Montador; Mestre em Comunicação, Arte e Cultura pela Universidade do Minho; Especialista em Educação a Distância pelo SENAC-GO, Graduado em Fotografia e Imagem pela Faculdade Cambury.

Email: renato.prado@ifg.edu.br

Morada: Instituto Federal de Goiás, Avenida Assis Chateaubriand, $n^{\circ}{ }_{1658}$, Setor Oeste. CEP 74130-012. Goiânia, Brasil

* Submetido: 14-09-2018

* Aceite: 02-01-2019 